\title{
TRANSDISCIPLINARIDADE PARA SE ENTENDER O DESIGN THINKING
}

Ida Elisabeth Benz

DAD / PUC-Rio

ida.e.benz@gmail.com

Claudio Freitas de Magalhães

DAD / PUC-Rio

claudio-design@puc-rio.br

Resumo: O design thinking começa a ser ensinado em business schools pelo mundo inteiro, mas profissionais de áreas externas ao design sentemse confusos com as opiniões contraditórias de diversos autores sobre este método. Como os designers desenvolveram uma mentalidade intermediária entre o pensamento científico e artístico, eles acabaram expandindo a causalidade linear e unidirecionalidade da lógica clássica e fazem uso intuitiva e empiricamente de uma causalidade em círculo (não linear) e multireferencial. Este artigo demonstra os paralelos entre os conceitos da proposta lógico-teórica de pensamento apresentada pela metodologia da transdisciplinaridade e o modo de pensar dos designers, defendendo a ideia de que pensamento transdisciplinar já vem sendo usado por esses profissionais.

Palavras-chave: Design thinking, metodologia da transdisciplinaridade, causalidade multireferencial

Abstract: The design thinking begins to be taught in business schools all over the world, but professionals from areas outside the design are confused by the contradictory opinions of various authors regarding this method. As the designers have developed an intermediate mentality between scientific and artistic thought, they ended up expanding the linear causality and one-pointedness of classical logic, making an intuitive and empirically use of a circle causality (non-linear) and with multireferentiality. This article demonstrates the parallels between the concepts of logicaltheoretical proposal of ideas presented by the methodology of transdisciplinarity and the way of thinking of designers, defending the idea that transdisciplinary thought has already been used by these professionals.

Keywords: Design thinking, methodology of transdisciplinarity, multireferential causality 


\section{INTRODUÇÃO}

Nos últimos 20 anos os conceitos de gestão, como por exemplo, estratégias competitivas, benchmarking, qualidade total, etc foram amplamente difundidos a ponto de deixarem de se tornar diferenciais, pois os concorrentes diretos acabam tendo acesso aos mesmos tipos de análises e chegam a conclusões mais ou menos parecidas (Coutinho, in: Martin, 2010). Além disso, com a velocidade da vida moderna, antes mesmo das análises ficarem prontas surgem mudanças tecnológicas, novos concorrentes, mudanças nas políticas públicas, etc. que tornam os resultados de sua implementação pouco marcantes.

Nesta lacuna, autores ligados ao design encontram uma chance de mostrarem que o design pode ser um instrumento que cria um diferenciador frente aos concorrentes, apresentando-o como outra forma de se pensar, criar e forjar relacionamentos com consumidores. E no inicio deste milênio, business schools no mundo inteiro começam a criar cursos que pretendem apresentar e ensinar aos gestores das empresas a experiência "prática" dos design thinkers.

Mas a difusão desse processo de pensamento entre profissionais fora da área do design acaba enfrentando algumas dificuldades, já que, segundo Kimbell (2009), o termo design thinking por sua literatura contraditória se torna confuso pela falta de descrição mais clara. A diversidade de opiniões que existe sobre o "mesmo" processo acaba transmitindo para os profissionais de outras áreas ligadas a inovação uma sensação de falta de clareza e coerência. Como Ling (2013) destaca, o aprendizado do design thinking por "não designers" pode se tornar muito frustrante, já que eles se sentem "perdidos" com essas opiniões contraditórias para guiá-los neste "território ainda não desbravado".

Muitos autores acima citados acreditam que é preciso se começar a re-pensar o design thinking e este artigo busca participar dessa discussão. Como o design não segue os paradigmas do pensamento científico cartesiano - já que o saber do design é um saber que se expressa para o seu entorno como um "saber do olhar", um "saber dos sentidos" e onde não se pode realizar a disjunção sujeito-objeto - os autores do artigo propõem que é preciso se buscar por novos enquadramentos teóricos e metodológicos que ajudem a entender o mundo complexo, único e imprevisível do design.

\section{O SABER DO DESIGNER}

A impossibilidade de se adequar a disjunção do sujeito-objeto faz com que o design não se enquadre como conhecimento puramente científico. Pois ele conjuga o conhecimento científico ligado aos métodos do projeto ao talento, à habilidade e à intuição do designer. Para Pazmino (2010) o design pertenceria ao campo da "artecientífica", já que no meio acadêmico/profissional muitos defendem que o "design se aprende fazendo", pois muitos conhecimentos se formam por meio da prática.

Desde o final do século passado Cross (1982) já nos aponta que o design tem um modo particular de saber, de conhecer e de descobrir sobre as coisas, diferente das disciplinas ligadas a área das ciências ou, até mesmo, as ligadas à área das humanas. Ele chamaria o design de uma "terceira cultura" do conhecimento, que não foi ainda reconhecida pelas outras duas por não ter sido, do ponto de vista do autor, adequadamente nomeada ou articulada. Buscando melhor exemplificá-la Cross (1982) 
tentou tornar mais claro as diferenças das 3 culturas através da comparação do design em relação às outras duas, compiladas pelos autores do artigo no Quadro 1.

Quadro 1 - As três culturas do conhecimento

\begin{tabular}{|l|l|l|l|}
\hline & Ciências & Humanas & Design \\
\hline Os valores & $\begin{array}{l}\text { objetividade, } \\
\text { racionalidade, } \\
\text { neutralidade e uma } \\
\text { preocupação com a } \\
\text { "verdade" }\end{array}$ & $\begin{array}{l}\text { subjetividade, } \\
\text { imaginação, compromisso } \\
\text { e uma preocupação com } \\
\text { a "justiça" }\end{array}$ & $\begin{array}{l}\text { praticidade, } \\
\text { engenhosidade, empatia, } \\
\text { e uma preocupação com } \\
\text { a “adequação" }\end{array}$ \\
\hline $\begin{array}{l}\text { Os métodos } \\
\text { apropriados }\end{array}$ & $\begin{array}{l}\text { controle, } \\
\text { experimentação, } \\
\text { classificação, análise }\end{array}$ & $\begin{array}{l}\text { analogia, metáfora, } \\
\text { crítica, avaliação }\end{array}$ & $\begin{array}{l}\text { modelagem, criação de } \\
\text { pattern, síntese }\end{array}$ \\
\hline $\begin{array}{l}\text { O fenômeno de } \\
\text { estudo }\end{array}$ & o mundo natural & a experiência humana & $\begin{array}{l}\text { o mundo feito pelo } \\
\text { homem }\end{array}$ \\
\hline
\end{tabular}

Fonte: Benz, 2014, p.22, com base em Cross, 1982

Outro ponto importante a ser abordado é que o modo do designer se aproximar de questões e problemas se dá através de processos mentais diferentes dos de outras atividades: enquanto os profissionais de outras atividades são treinados para atuarem dentro da realidade - "o que é" -, os designers se preocupam também com uma visão - "o que poderia ser" (Neumeier, 2010).

O designer se utiliza do raciocínio abdutivo (que imagina que algo poderia existir) através de saltos lógicos da mente. Este termo foi cunhado, segundo Martin (2010), por Charles Sanders Peirce que acreditava que as novas ideias não surgem das formas convencionais da lógica declarativa, que engloba os modos fundamentados na tradição científica:

- a lógica dedutiva - que prevê o que deve ser, através de conclusões tiradas do geral para o específico;

- e, a lógica indutiva - que conclui o que é pertinente e/ou eficiente, a partir de observações do específico para o geral.

Como esses dois modos de pensar se utilizam de dados do passado para gerarem as suas comprovações, eles são perfeitos para tarefas de natureza algorítmica, onde existem formulas conhecidas (Neumeier, 2010). Mas quando as tarefas não são governadas por regras pré-definidas, como é o caso no surgimento de novas ideias, esses dois modos de pensar podem induzir a erros em razão dos parâmetros definidos para os mesmos criados a partir de realidades não mais vigentes.

Trabalhando com "o que poderia ser" em vez do com "o que é", o designer faz uso do pensamento intuitivo, fugindo de um enfoque linear: ação $A$, depois ação $B, C$, $D, E$ consecutivamente. "A mente intuitiva reordena os itens como $C-B-D-A$, e inclui R-K-Z-P, para completar" (Neumeier, 2010, p. 34).

Para Couto (1997) a dificuldade de fazer uso de tomadas de decisões através de um processo linear simples durante um projeto de design se deve ao fato dele se debruçar, muitas vezes, sobre problemas complexos e não estruturados. Buscando respostas para seus questionamentos o designer transita em diversas áreas de conhecimento, o que impede que o design se vincule a metodologias de conhecimento contidas dentro do pensamento disciplinar. Segundo Bomfim (1997), o design não 
possui um campo fixo de conhecimento, seja ele linear-vertical (disciplinar), ou linearhorizontal (interdisciplinar). A teoria do design é instável, e provavelmente, tem uma constituição transdisciplinar, que se move entre disciplinas tradicionais, para buscar as informações necessárias, variando conforme a natureza do problema tratado.

Dykes et al. (2009) sugeriu um novo enquadramento disciplinar, transversal, multi, inter e transdisciplinar para a prática de design, classificando tanto o trabalho individual de designers, quanto ajuda na compreensão da dinâmica do trabalho em grupo nas equipes de projeto.

"[0] design transdisciplinar: envolve conhecimentos ou conceitos a partir de pelo menos duas disciplinas em que nenhuma delas assuma a predominância. Este trabalho será inovador, constituindo novos conhecimentos, conceitos e objetos, e vai significar um novo tipo de prática, que é uma combinação de conhecimentos disciplinares fundidos para criar uma forma híbrida recém-unificada" (Benz, 2014, p. 98).

E em 2010, The New School for Design da Parsons em Nova York criou o MFA Transdisciplinary Design, respondendo a novas necessidades para a prática do design, onde os estudantes são incentivados a realizar projetos práticos, trabalhando em equipes transdisciplinares e abordando os temas através de perspectivas múltiplas.
"Jamer Hunt, diretor deste programa, em uma palestra proferida na PUC-Rio em 2014, afirmou que o design para o século XXI não é mais centrado apenas em objetos, mas também em soluções dentro de sistemas" (Benz, 2016, p.36).

Benz (2012), descobriu um paralelo surpreendente ao comparar a metodologia da transdisciplinaridade a conceitos do design e do design thinking, como pode ser visto no Quadro 2. Quadro 2 - Paralelos entre a metodologia da transdisciplinaridade e o modo de atuação e visão do
design thinking

\begin{tabular}{|l|l|l|}
\hline \multicolumn{2}{|l|}{ metodologia da transdisciplinaridade } & $\begin{array}{l}\text { exemplos do design e do design } \\
\text { thinking }\end{array}$ \\
\hline \multirow{2}{*}{$\begin{array}{l}\text { física quântica e os níveis de } \\
\text { realidade }\end{array}$} & descontinuidade & os saltos lógicos da mente \\
\cline { 2 - 3 } & não separabilidade & jrocesso de reflexão em ação \\
\cline { 2 - 3 } & & "o que é" e “o que poderia ser" \\
\cline { 2 - 3 } & causalidade global & processo do saber dinâmico \\
\hline \multirow{2}{*}{ complexidade } & não redução da realidade & modelo circular de Tim Brown \\
\cline { 2 - 3 } & não linearidade causal & pensamento intuitivo \\
\hline \multirow{2}{*}{ a lógica do terceiro incluído } & $\mathrm{A}+$ não-A = T & raciocínio abdutivo \\
\cline { 3 - 3 } & & pensamento equivocado \\
\hline
\end{tabular}

Fonte: Benz e Magalhães, 2012. 


\section{A MEDOLOGIA DA TRANSDISCIPLINARIDADE APLICADA AO DESIGN}

A complexidade e as incertezas estão sempre presente no nosso mundo atual e o conhecimento de uma disciplina muitas vezes não é o suficiente para se entendê-lo, a necessidade por uma reforma de pensamento começa a ser percebida e proposta através de novos enquadramentos teóricos e metodológicos.

"O pensamento que une substituirá a causalidade linear e a unidirecionalidade por uma causalidade em círculo e multireferencial; corrigirá a rigidez da lógica clássica pelo diálogo capaz de conceber noções ao mesmo tempo complementares e antagonistas, e completará o conhecimento da integração das partes em um todo, pelo reconhecimento da integração do todo no interior das partes" (Morin, 2003, p. 92-93).

Em meados dos anos 60 do século passado, surgiu um novo enquadramento, inicialmente, chamado de interdisciplinar. Mas, segundo Paviani (2003), em razão do uso indiscriminado do termo gerou-se uma multiplicidade de significados, sendo necessário criar diferenciações para os conceitos através dos prefixos pluri ou multi, inter e trans - gerando assim mais uma confusão entre os respectivos termos.

Por isso, antes de se apresentar a metodologia da transdisciplinaridade proposta por Nicolescu (in: Nicolescu et al., 2000) é importante reapresentar o conceito definido pelo autor para o termo transdisciplinaridade:

- como o prefixo trans indica, diz respeito àquilo que está ao mesmo tempo entre as disciplinas, através das disciplinas e além de qualquer disciplina. Seu objetivo é a compreensão do mundo presente, para o qual um dos imperativos é a unidade dos conhecimentos.

Iribarry (2003) afirma que na transdisciplinaridade não existe o domínio de uma disciplina, ela tem "como ambição a unificação, em suas diferenças, do objeto e do sujeito: o sujeito conhecedor faz parte integrante da natureza e do conhecimento" (Iribarry, 2003, p. 486).

Segundo o Nicolescu (in: Nicolescu et al., 2000), a metodologia da transdisciplinaridade se baseia em 3 pilares: $i$. a física quântica e os níveis de realidade, ii. a complexidade, e iii. a lógica do terceiro incluído. E segundo o mesmo autor, esses 3 pilares são necessários para se idealizar métodos e modelos transdisciplinares adequados a estudos de situações particulares e práticas.

As pesquisas ligadas à física quântica - o primeiro pilar da metodologia de Nicolescu -, que se iniciaram com a descoberta de Max Planck no começo do século XX, colocou em questão conceitos, ou pilares como Morin (2007) os denominou, sobre o qual o mundo científico repousava deste da época de Aristóteles: i. o primeiro pilar é a ordem, a regularidade, a constância e sobretudo o determinismo absoluto; ii. o segundo pilar é a separabilidade, ou reducionismo; e iii. o terceiro pilar é o valor de prova absoluta fornecida pela indução e pela dedução, e pelos princípios aristotélicos que estabelecem a unidade da identidade e a recusa da contradição.

A desconstrução dessas verdades "irrestritas" iniciou-se com o testemunho da descontinuidade no campo da física, já que uma partícula quântica poderia aparecer em qualquer lugar não previsto tornado impossível de se traçar uma trajetória pré- 
determinada, e por consequência, abalando a primazia do conceito de causalidade local como se conhece no mundo percebido pelo observável da macrofísica.

Goswami (2012) exemplifica, de um modo mais claro para leigos, como se dá esse movimento da partícula quântica: um elétron pula de uma órbita atômica para a outra através de movimentos descontínuos, sem atravessar o espaço interveniente. Esse movimento é chamado de salto quântico (Figure 1). No caso de muitas órbitas disponíveis não se consegue predizer para qual delas o elétron pulará. Tampouco se pode dizer quando ele vai pular. Existem apenas probabilidades.

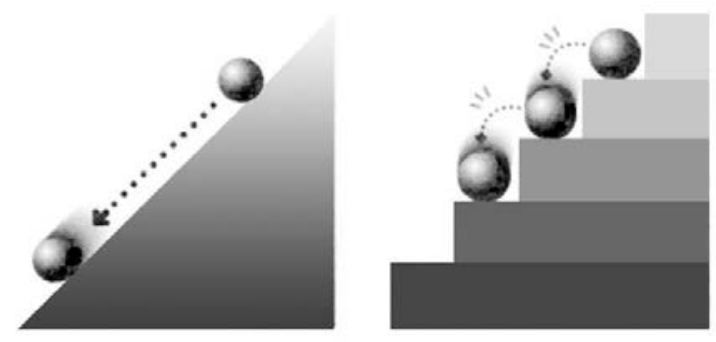

Figura 1 - A linearidade do movimento na macrofísica versus o salto quântico do elétron. Fonte: Goswami, 2012, p. 47.

O mesmo autor ainda destaca que o salto quântico abre uma nova visão do mundo, já que antes de se detectar o lugar para aonde o elétron saltou, existe uma onda de possibilidades, e que o "nosso olhar (a mensuração) entra em colapso com sua onda de possibilidades, provocando um único acontecimento" (Goswami, 2012, p. 49). Portanto segundo o autor o "nosso" olhar muda as coisas, pois a partir da mesma onda vários acontecimentos ligados a olhares diversos podem ser gerados, não existindo assim "verdades absolutas" como o pensamento clássico apregoa. O autor compara também essas probabilidades à capacidade criadora, afirmando que como não há um algoritmo completo, ou seja, um determinismo completo, através dos conceitos do "mundo quântico, abre-se uma janela para a verdadeira criatividade, para o verdadeiro novo" (Goswami, 2012, p. 46-47).

A esse conceito da não linearidade se uni um segundo, o da não separabilidade. Ele assinala que objetos que no mundo da macrofísica não interagiriam mais entre si em razão da distância, no mundo quântico continuam a interagir qualquer que seja o seu afastamento, mostrando que existe uma causalidade global, que engloba um sistema de todas as entidades físicas em um único conjunto.

Segundo Nicolescu (in: Nicolescu et al., 2000), a existência de correlações não locais expande o campo da verdade e da realidade, já que não existe apenas o mundo da macrofísica. A realidade, segundo Random (in: Nicolescu et al., 2000), passa a se dividir em três níveis distintos: $i$. o mundo racional, associado ao mundo "observável" do espaço e tempo contínuos; ii. o mundo do vibratório ou quântico, associado à não separabilidade; iii. e, o mundo subquântico, que o autor associa à autoconsciência da partícula e a unicidade instantânea de todas as coisas; o cósmico, a união do visível com o invisível - ou seja à causalidade global, que para Goswami (2012) se equivaleria ao inconsciente coletivo.

Segundo Bohr (2008), como qualquer afastamento radical da explicação costumeira, a física quântica encontrou mesmo entre muitos físicos e filósofos, principalmente em razão da renúncia a ideia de determinismo causal, um campo fértil 
para dúvidas. Ela colocava em questão o próprio ato de conhecer definido na tradição clássica, pois a indivisibilidade dos fenômenos quânticos em relação à localização espaço-temporal impossibilita que qualquer experimento possa ser repetido de modo inambíguo, como a ciência - inclusive as humanas - apregoa.

Mas mesmo que essas mudanças descobertas pela física quântica remontem a primeira metade do século passado, como o arcabouço conceitual característico da física clássica ou macrofísica dominou a mente humana ao longo dos últimos três séculos, ainda hoje vemos que a maioria das disciplinas busca se "enquadrar" dentro dessa matriz de pensamento clássica. Essa matriz se tornou "um meio lógico de compreendermos vastos campos da experiência" (Bohr, 2008, p. 100), e assim dados divergentes não são percebidos como complementares, mas como antagônicos, deixando as pessoas "perdidas" como no exemplo comentado por Ling (2013) das "opiniões contraditórias" a respeito do design thinking.

O que muitas vezes não é percebido é que as pessoas já convivem com esses conceitos no seu dia a dia, como por exemplo, o conceito da complementaridade tão presente na arte moderna pós Cezánne (Domingues, 2001). Não existe nada que melhor exemplifique esta afirmação do que a sequência de pinturas e aquarelas de Cezánne da Montanha de Saint Victoire. Segundo o mesmo autor, nela vê-se que o pintor abandona o conceito de pintura como uma encenação de cenas imaginadas ou extroversão de um sonho - ou seja, do idealizado - e começa a encará-la como um estudo preciso das aparências, buscando retratar a realidade sem abandonar as sensações de um sujeito. São como se fossem os diversos colapsos do olhar do pintor com a onda de possibilidades de visões da montanha materializadas em imagens muito distintas (Figura 2).

Essa pesquisa de Cézanne revela que a perspectiva vivida, a da percepção do nosso olhar, não é igual a perspectiva geométrica ou fotográfica, e consequentemente que a realidade não pode ser resumida em uma única imagem, uma única "verdade". Nela podemos ver que "cada quadro é, ao mesmo tempo, a mesma montanha e é outra montanha" (Domingues, 2001).
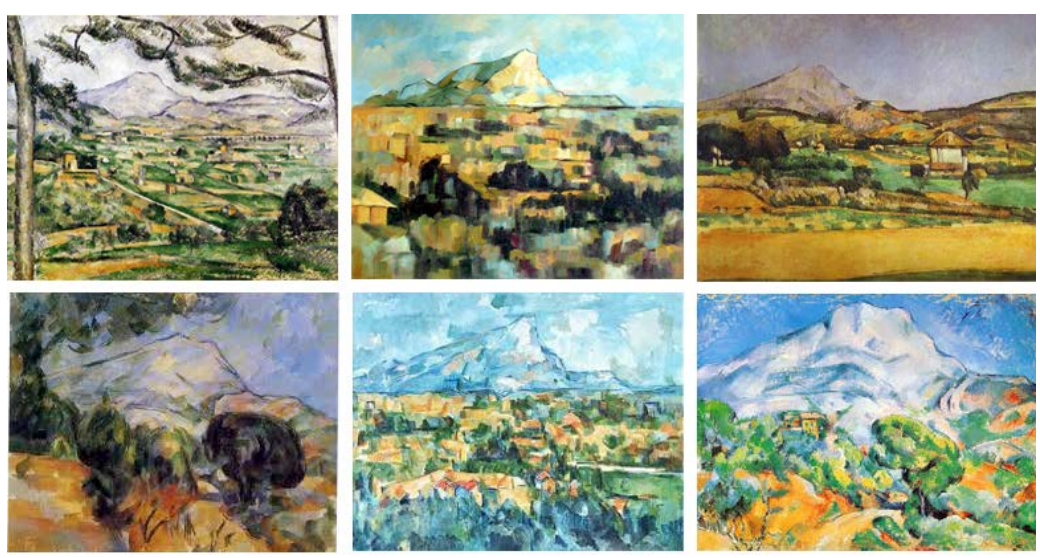

Figura 2 - Exemplos de pinturas e aquarelas de Cézanne da Montanha de Saint Victorie. Fonte: Benz, 2014, p. 106.

Já compreendemos nas artes atualmente, que nenhuma das representações é a "certa" tornando as outras as "erradas". Elas registram momentos distintos, dependo não somente da localização do pintor naquele momento, do seu humor, mas também 
do material que ele dispõe, de sua técnica, conhecimento e experiência com cada um deles. Para Domingues (2001) esse princípio da complementaridade para se tentar esgotar um objeto que não pode ser compreendido dentro de um quadro único, e inaugura a reflexão atual sobre a impossibilidade de se reduzir a realidade a uma única linguagem, contendo-a em um único discurso, relançando a questão da multi, da inter e transdisciplinaridade. E é exatamente nesta aceitação da complementaridade dos fenômenos individuais que reside a beleza da teoria de Nicolescu, pois demonstra a importância da visão de cada sujeito sob um fenômeno, uma experiência, um projeto, etc. pois é na soma de todas essas visões que se poderá buscar uma totalidade de seu entendimento.

O segundo pilar da metodologia da transdisciplinaridade, a complexidade pode ser decorrência dessa não existência de "errados", exemplificada anteriormente, e, portanto, da impossibilidade de se reduzir a realidade. Morin (2007) afirma que "o desafio da complexidade se intensifica no mundo contemporâneo já que nos encontramos em uma época de mundialização". A complexidade está presente no nosso mundo e nas nossas relações sociais, consequentemente a complexidade também está presente na nossa ciência - que busca observar e entender o que cerca o ser humano.

Esta relação entre o todo e as partes, na visão clássica onde reina a linearidade causal, gerou a crença de que tudo poderia ser separado em partes, como partes de uma máquina. Nela os componentes - até mesmo de algo complexo - fazem parte de um conjunto em uma relação fixa, baseada na realidade visível e, portanto experimentável. Com a existência de diversos níveis de realidade e da não previsibilidade defendido pela física quântica a complexidade torna-se uma complexidade desordenada. E quem quiser entendê-la precisa buscar o entendimento sistêmico das partes, tendo sempre em mente que elas são dinâmicas e que podem evoluir e possuir uma plasticidade, que impede que se possa conhecer o todo através da simples soma dos conhecimentos de suas partes. O mesmo autor destaca que já existem disciplinas científicas que não fragmentam e compartimentam o campo do saber, pois "tem por objeto não um setor ou uma parcela, mas um sistema complexo, que forma um todo organizado" (Morin, 2003, p. 26-27), como por exemplo, a ecologia e a cosmologia.

Como no exemplo de um rosto humano uma análise das partes separadas, pode até determinar o formato ideal para bocas, olhos, nariz, etc, mas é o conjunto, ou melhor, a relação de um elemento da face com o todo que determina se uma pessoa é bela ou não. Nesta brincadeira feita pela Star Magazine (Figura 3), uma revista de celebridades que resolveu "montar" a face perfeita a partir de exemplos mais pedidos aos cirurgiões plásticos de Beverly Hills - os olhos do 007 Daniel Craig, o nariz de Leonardo DiCaprio, os lábios de Matt Damon, o queixo de Batman Christian Bale e os cabelos de John Stamos -, pode-se ver que essa afirmação se confirma, e que a união das partes "perfeitas" não criam um rosto mais atraente dos que os "originais". 


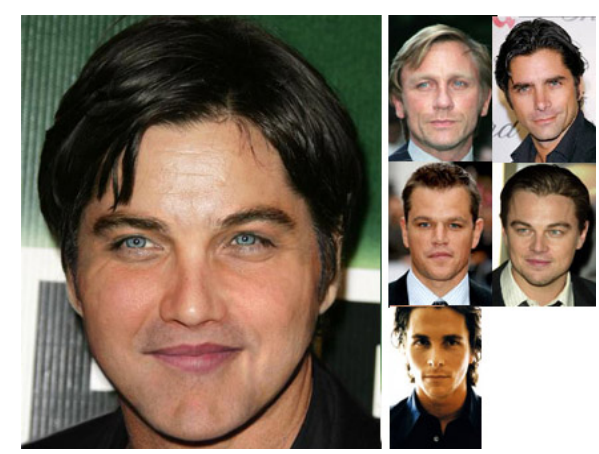

Figura 3 - Perfect face.

Fonte: Star Magazine, 2008.

O último pilar da metodologia da transdisciplinaridade é a lógica do terceiro incluído. Ela gerou, a princípio, um escândalo intelectual (Nicolescu, in: Nicolescu, et al., 2000), já que a lógica clássica é baseada em três axiomas, que se cristalizaram no nosso entendimento do mundo que nos cerca:

1: $A$ é $A$ = axioma da identidade;

2: A não é "não-A" = axioma da não contradição; excluído.

3: não existe um terceiro termo $\mathrm{T}$ (de "terceiro incluído) = axioma do terceiro

Esses três axiomas, tão incorporados ao modo de pensar do homem moderno, torna impossível que a lógica do terceiro incluído seja compreendida como aceitável em um primeiro momento. Quando Stéphane Lupasco formaliza o axioma do terceiro incluído - que afirma que "existe um terceiro termo $\mathrm{T}$ que é ao mesmo tempo $\mathrm{A} e$ 'não-A'” (Nicolescu, in: Nicolescu et al., 2000, p. 26) - é compreensível o surgimento desse estranhamento. No mundo racional, associado ao mundo "observável" do espaço e tempo contínuos, deste axioma poderia se derivar afirmações como o dia é noite, o preto é branco, o homem é mulher, já que segundo o autor, na "lógica do terceiro incluído os opostos são antes contraditórios: a tensão entre os contraditórios promove uma unidade que inclui e vai além da soma dos dois termos" (Nicolescu, in: Nicolescu et al., 2000, p. 28).

Mas no mundo quântico a realidade é diferente. A ilustração do experimento mental da fenda dupla ajuda a se entender mais facilmente a lógica do terceiro incluído Esse experimento da fenda dupla (Figuras $4 a$ e $4 \mathrm{~b}$ ) pode-se perceber uma característica da mecânica quântica que vai contra ao nosso modo intuitivo de pensamento (Bezerra, 2013). Um elétron ao ter a sua passagem "liberada" por um anteparo opaco com duas fendas registra em uma tela, por exemplo, fosforescente, colocada atrás desse anteparo uma imagem que não é uma simples soma da forma das duas fendas. Em razão da propagação do elétron em forma de ondas cria-se pela difração, um terceiro padrão formado através da interferência das duas ondas entre si (Figura 4b).

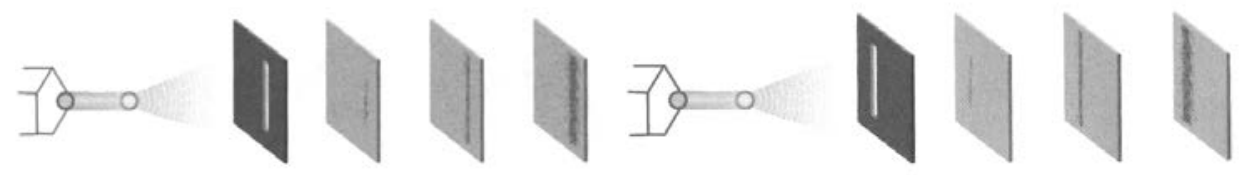

Figura 4a - "Experimento da Fenda Dupla com apenas uma fenda aberta no anteparo". Fonte: Bezerra,2013, p. 119-120. 


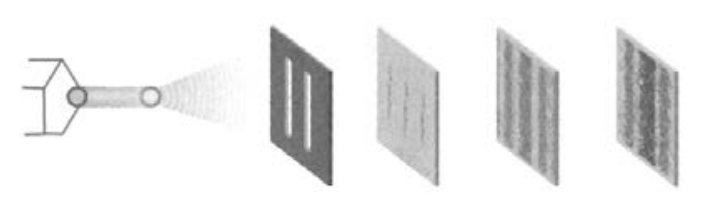

Figura 4b - "Experimento da Fenda Dupla com as duas fendas abertas, formando um padrão de interferência que é diferente da simples soma das duas condições anteriores"

Fonte: Bezerra, 2013, p. 120.

Esta zona de interferência formada em razão da superposição das duas ondas, fez com que fosse possível se perceber que os conhecimentos de duas disciplinas, não apenas se somam como dois "tijolos de um edifício", mas criam uma área de atuação conjunta e imprevisível pelos padrões das duas disciplinas que a originaram.

Outro ponto importante a ser destacado é que apesar de Nicolescu (in: Nicolescu et al., 2000) apresentar exemplos de A e "não-A" como dia e noite, preto e branco, o homem é mulher, o termo "não-A" não precisa se restringir apenas ao oposto de A, mas a tudo que "não é $A$ ", ou seja, B, C , D , 1, 2 , 6 etc são também "não$A$ "s. Pensando assim, pode-se perceber que as inovações radicais poderiam ser encaixadas dentro desta máxima do terceiro incluído, como o exemplo da criação dos telefones celulares nos mostra.

Desde o inicio da década de 1980 quando o primeiro telefone celular foi lançado nos EUA - um modelo grande e que pesavam em torno de $1 \mathrm{~kg}-$, até os dias de hoje, "o avanço da tecnologia contribuiu bastante, os aparelhos de celular foram evoluindo, ganhando cada vez mais funções e ficando cada vez menores e mais leves" (Monteiro e Ramalho, 2010). Se antes o celular "só" servia para fazer e receber chamadas, hoje foi incorporado ao nosso cotidiano exercendo outras atividades inimagináveis a priori, como por exemplo, mandar mensagem, jogar, tirar foto, filmar, ouvir músicas, ver vídeos, acessar a internet, ver televisão, etc.

Olhando-se mais detalhadamente para essas funções "anexadas" ao celular, percebe-se que elas exemplificam a máxima do terceiro incluído. Ou seja, os "não-As" no telefone celular seriam as câmeras fotográficas, os rádios, os gravadores de voz e imagem, os aplicativos, etc. E pode-se perceber que a cada inclusão de "não-As" o modo das pessoas se relacionarem com o objeto foi se tornando diferente, como se pode perceber através de mudanças que acabaram transformando o modo de se relacionar o celular, já que o principal canal de interação entre a pessoa e este objeto não é mais a audição, mas sim a visão (Figura 5).

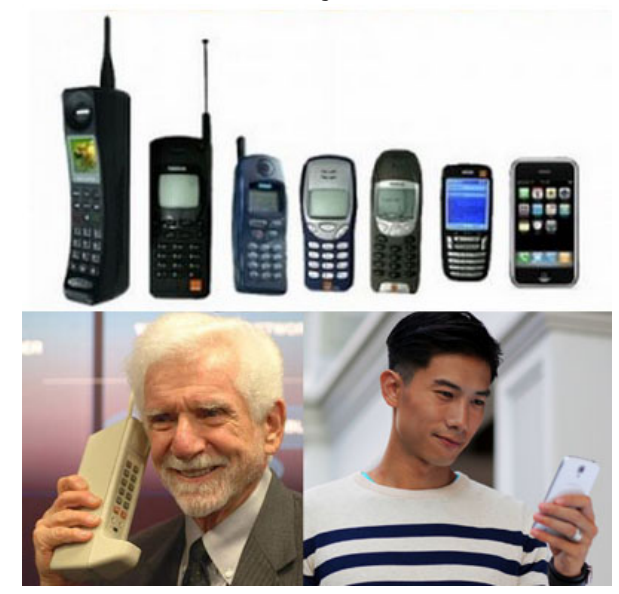

Figura 5 - "Evolução do telefone celular".

Fonte: Benz, 2014, p. 109 com base em MONTEIRO e RAMALHO (2010). 


\section{CONCLUSÃO}

Atuando com um modo de pensar intermediário entre o pensamento científico e o pensamento artístico, o designer já vem operando através de uma visão transdisciplinar há muitos anos, como a teoria da "terceira cultura do conhecimento" identificada por Cross (1982) insinua ao defender que design extrapolaria uma soma "simples" das culturas da ciência e humanas e conseguiria unir a contradição do pensamento objetivo e do pensamento subjetivo.

Olhando-se mais atentamente alguns conceitos do design e do design thinking, e comparando-os a metodologia da transdisciplinaridade pode-se perceber que existe um paralelo surpreendente entre ambos, como por exemplo: a descontinuidade, não separabilidade e a causalidade global do 10 pilar - com os conceitos dos saltos lógicos da mente (Peirce, in: Martin, 2010) e o processo de reflexão em ação (Neumeier, 2011), a junção de análise e síntese (Martin, 2010) e "o que é" e "o que poderia ser" (Neumeier, 2011), o processo do saber dinâmico (Neumeier, 2011), respectivamente a não linearidade causal do $2 \circ$ pilar - com o pensamento intuitivo do designer - e, a lógica do terceiro incluído do 3o pilar - com o raciocínio abdutivo (Martin, 2010) e o pensamento equivocado (Neumeier, 2011).

Muitos conceitos do design thinking, que parecerem incoerentes sob a ótica da lógica clássica, encontram respaldo sob a ótica da metodologia da transdisciplinaridade apresentada por Nicolescu (in: Nicolescu et al., 2000). Através dela, o designer ganha as ferramentas necessárias para explicar o seu modo de pensar, se libertando das amarras da previsibilidade e reprodutibilidade, da delimitação no domínio de competência do conhecimento (reducionismo) e da dissociação entre o sujeito e o objeto que fundamentam a lógica clássica.

$E$, sua proximidade com esse novo olhar não fragmentado pode ser uma das razões que explicariam o porquê do design thinking, ou seja, o modo particular dos designers verem e pensarem o mundo, estar sendo celebrado como um novo instrumento de gestão da inovação: percebeu-se empiricamente que esse modo holístico dos designers de se aproximarem das questões se adapta melhor a complexidade e a não previsibilidade do mundo contemporâneo.

\section{REFERÊNCIAS}

BENZ, Ida Elisabeth. Design Inovador: mandala transrelacional de abordagens criativas. 289 f. Tese (doutorado) - Pontifícia Universidade Católica do Rio de Janeiro, Departamento de Artes e Design. 2014.

\section{Colaboração interdisciplinar no design: práticas criativas das}

escolas de samba como um exemplo possível. In: Interdisciplinaridade / Grupo de Estudos e Pesquisa em Interdisciplinaridade (GEEducação: Currículo - Linha de Pesquisa: Interdisciplinaridade - n.7 (out. 2015) - Paulo: PUCSP, 2015.

BENZ, Ida Elisabeth e MAGALHÃES, Claudio Freitas. Design, inovação e transdisciplinaridade - uma relação oculta. In: Anais P\&D Design 2012 - 10 Congresso Brasileiro de Pesquisa e Desenvolvimento em Design. 2012, São Luis. Disponível em:https://pucrj.academia.edu/IdaBenz Acesso em: 10/01/2015. 
BEZERRA, Daniel. Pura picaretagem: como livros de esoterismo e autoajuda distorcem a ciência para te enganar. Saiba como não cair em armadilhas. São Paulo: LeYa, 2013.

BOHR, N. Física atômica e conhecimento humano: ensaios 1932-1957. 4aa. edio de Janeiro: Contaponto, 2008

BOMFIM, Gustavo Amarante. Fundamentos de uma teoria transdisciplinar do design: morfologia dos objetos de uso e sistemas de comunicação. Estudos em Design. V. V. n 2, dez. 1997.

COUTO, Rita Maria de Souza. Design como corpo de conhecimento. Em: Movimentos interdisciplinares de designers brasileiros em busca de educação avançada. Tese (doutorado) - Pontifícia Universidade Católica do Rio de Janeiro, Departamento de Letras. 1997.

CROSS, Nigel. Designerly ways of knowing. DESIGN STUDIES, vol 3, no 4. October 1982. Disponível na internet por http em:

<http://design.open.ac.uk/cross/documents/DesignerlyWaysofKnowing.pdf> Acesso em 22 de nov. 2013.

DOMINGUES, Ivan. Conhecimento e transdisciplinaridade. Belo Horizonte: Editora UFMG: IEAT, 2001

DYKES, THOMAS H. et al. Towards a new disciplinary framework for contemporary creative design practice. CoDesign, Vol. 5, No. 2, June 2009, 99-116. Disponível em: http://doczine.com/bigdata/2/1383674249_0c6ab01180/32bfe50c85278bb811.pdf Acesso em: 22/2/2014.

GOSWAMI, Amit. Criatividade para o século 21: uma visão quântica para a expansão do potencial criativo. São Paulo: Aleph, 2012

KIMBELL, Lucy. Beyond design thinking: Design-as-practice and designs-in-practice. CRESC Conference, Manchester. 3o Dec, 2013. Disponível na internet por http em: <http://www.lucykimbell.com/stuff/CRESC_Kimbell_v3.pdf> Acesso em $30 \mathrm{de}$ dez. 2013.

LING, Brian. Design thinking is killing creativity, 2010. Disponível na internet por http em: <http://pt.slideshare.net/designsojourn/design-thinking-is-killing-creativity> Acesso em 30 de dez. 2013.

MARTIN, Roger L. Design de negócios: por que o design thinking se tornará a próxima vantagem competitiva dos negócios e como se beneficiar disso. Rio de Janeiro: Elsevier, 2010.

MONTEIRO, Danielle e RAMALHO, Rennata. (Maio de 2010). História e evolução do nosso querido celular. Maio de 2010. Disponível na internet por http em: <http://rpuerj.blogspot.com.br/2010/05/historia-e-evolucao-do-nosso-querido.html> Acesso em 8 de out. 2013.

MORIN, Edgar. A cabeça bem-feita: repensar a forma, reformar o pensamento. $8^{\mathrm{a}}$ ed. Rio de Janeiro: Bertrand Brasil. 2003 Educação e complexidade: os sete saberes e outros ensaios. 4ạ ed. São Paulo: Cortez, 2007. 
NEUMEIER, Marty. A empresa orientada pelo design. Porto Alegre, Bookman. 2011. NICOLESCU, Basarab et. al. Educação e Transdisciplinaridade. Brasília: UNESCO, 2000. PAVIANI, Jayme. Disciplinaridade e Interdisciplinaridade. 2003. Disponível na internet por http em: <http://www.humanismolatino.online.pt/v1/pdf/C002_02.pdf> Acesso em 15 de nov. 2011.

PAZMINO, Ana Veronica. Modelo de ensino de métodos de design de produto. 2010. 2v. 454 f. Tese (doutorado) - Pontifícia Universidade Católica do Rio de Janeiro, Departamento de Artes e Design. 2010.

STAR MAGAZINE. Perfect Face. February, 2008. Disponível em: http://www.commonsenseevaluation.com/2008/02/25/star-magazines-perfect-face/ Acesso em: 22/2/2014. 